\title{
Naphthalene group containing side chain liquid crystalline polymers and their rheological behavior
}

\author{
Noordini M. Salleh • Md. Rezaul Karim Sheikh • \\ Rosiyah Yahya • Md. Rabiul Karim • Aziz Hassan
}

Received: 20 November 2012 / Accepted: 25 March 2013 /Published online: 7 April 2013

(C) The Author(s) 2013. This article is published with open access at Springerlink.com

\begin{abstract}
A new polymerizable macromer containing naphthalene ring in the mesogen, 4-butoxyphenyl 6-(6-(methacryloyloxy)hexyl)-2-naphthoate, has been synthesized. The chemical structure of the macromer was confirmed by FTIR, ${ }^{1} \mathrm{H}$ NMR, ${ }^{13} \mathrm{C}$ NMR and liquid crystal behavior was confirmed by polarized optical microscope (POM) and small angle X-ray (SAXS). Results from the POM showed nematic phase appearing at $101.9^{\circ} \mathrm{C}$ and smectic phase at $83.8^{\circ} \mathrm{C}$ while differential scanning calorimetry (DSC) suggested presence of a wide mesophase range between 50 and $104{ }^{\circ} \mathrm{C}$. This macromer was used to synthesize a series of side-chain liquid crystal polymers (SCLCPs) with different molecular weights having narrow polydispersity (PDI) values via living atom transfer radical polymerization (ATRP). The mesomorphic properties of the liquid crystal macromer and polymers were characterized by POM, DSC and SAXS. In addition, the frequency behavior of the polymers in a smectic phase is characterized by the storage modulus, $G$, leveling off, at low frequencies. Complex viscosities, $\left|\eta^{*}\right|$ of the smectic phase exhibited a shear thinning behavior over the shear rates investigated.
\end{abstract}

Keywords Side-chain liquid crystal polymer $\cdot$ Naphthalene . Mesophase $\cdot$ Rheology and smectic

N. M. Salleh • M. R. K. Sheikh $(\bowtie) \cdot$ R. Yahya $\cdot$ M. R. Karim $•$

A. Hassan

Department of Chemistry, Faculty of Science, University of

Malaya, 50603, Kuala Lumpur, Malaysia

e-mail: rksheikh@um.edu.my

M. R. K. Sheikh

e-mail: rksheikh@yahoo.com

\section{Introduction}

In recent years side chain liquid crystalline polymers (SCLCPs) have been of great interest because of their advantages arising from the properties of the polymer as well as liquid crystal behaviour. Polymers containing mesogenic side groups attached laterally in the main chain are known as side chain liquid crystalline polymers (SCLCPs) because of their liquid crystalline bulk properties [1]. SCLCPs exhibit unique properties such as high heat resistance, flame retardant, chemical resistance, dimensional stability, moldability, heat aging resistance, adhesion, low viscosity, weldable and comparatively low cost. The properties of SCLCPs depend on the different parameters, such as, the nature and length of the spacer, the type of mesogen [2-4], and the nature of the polymer backbone. In 1978, Ringsdorf et al. [5-7] developed the first side chain liquid crystal polymer and since then research in polymer liquid crystalline science and technological applications have dramatically increased. The macromolecular structure of SCLCPs depends on both the composition of the polymer main chain and the side chain with liquid crystalline character. Thus, the design and synthesis of SCLCPs can be fulfilled via proper selection of different polymer main chains and side chains to meet the practical applications.

Atom transfer radical polymerization (ATRP) is one of the most efficient, nitroxide-mediated and stable controlled/livingradical polymerization methods that have been used recently [8-11]. This method has been chosen in this study because it can be easily applied to a wide number of monomers which lead to polymer architectures with narrow polydispersities resembling living nature [12-14].

Recently, Jeyasheela and Subramaniam [15] synthesized SCLCPs containing chalcone moiety as a side group by free-radical polymerization using BPO as an initiator. They 
found good liquid crystalline and photolithographic properties of the synthesized polymers. On the other hand, Yang and Chang [16] studied the linear viscoelasticity and steady shear behavior of smectic phase of SCLCPs with a polysiloxane backbone. The smectic phase of the SCLCPs exhibited some interesting features such as an orientation under shear and a plateau in the terminal zone of dynamic shear modulus.

In our work, we have synthesized a new macromer having naphthalene moiety and optically active species in the mesogen. SCLCPs of the macromer were synthesized by living ATRP. The macromer and SCLCPs were characterized by ${ }^{1} \mathrm{H}$ NMR, ${ }^{13} \mathrm{C}$ NMR and FT-IR to confirm the chemical structures. The liquid crystal behavior of the macromer and polymers were investigated by POM, DSC, and SAXS. Molecular weight was measured by gel permeation chromatograph (GPC). Rheological studies were done as the measurements of viscoelastic properties can provide information on the local dynamics of the mesogens and the synthesized polymer chain.

\section{Experimental}

\section{Materials}

Chemicals and solvents were of reagent grades and purchased from Aldrich, Merck, ACROS, R\&M Chemicals and J. T. Baker. Acetone and methanol were distilled and kept anhydrous before used. Catalyst copper (I) bromide was purified successively by stirring in acetic acid and ethanol, and then dried. All of the other chemicals and solvents were used as received.

\section{Measurements}

${ }^{1} \mathrm{H}$ NMR and ${ }^{13} \mathrm{C}$ NMR measurements were performed with a JEOL spectrometer (Lambda $400 \mathrm{MHz}$ ). The FT-IR spectra of the macromer were recorded with a Spotlight 400 Perkin Elmer spectrometer with 16 scanning numbers using attenuated total reflectance (ATR) method. The wavelength was recorded from region 650 to $4000 \mathrm{~cm}^{-1}$ at room temperature. Thermal data were obtained using a Perkin Elmer Hyper DSC instrument. Each sample was heated and cooled at a scanning rate of $10{ }^{\circ} \mathrm{C} / \mathrm{min}$ under nitrogen atmosphere. The second heating and cooling runs were evaluated. The thermal decomposition temperature data were recorded under nitrogen atmosphere at a heating rate of $10^{\circ} \mathrm{C} / \mathrm{min}$ with a SDT Q600 thermogravimetric analyzer (TA Instrument). The liquid crystal phase transitions were investigated by an Olympus $\mathrm{BH}-2$ polarized light microscope (POM) equipped with Mettler Toledo hot stage FP-82 and the temperature scanning rate was determined at a rate of $1{ }^{\circ} \mathrm{C} / \mathrm{min}$. Small-angle X-ray scattering (SAXS) experiments were performed with NanoViewer equipped with a CCD camera (Rigaku Corp. Japan). The X-ray experiment was performed by using the $\mathrm{Cu} \mathrm{K}_{\alpha}$ radiation beam $(\lambda=1.541 \AA)$ which was converged and monochromatized by a Confocal Max Flax (CMF) mirror. $\mathrm{X}$-ray generator was a Rigaku Micro7 rotating anode generator $(40 \mathrm{kV}, 30 \mathrm{~mA})$. The diameter of the X-ray beam controlled by a 3 -slit optical system was set to $250 \mu \mathrm{m}$. The pellet sample was wrapped with aluminium foil and placed to the instrument. The temperature of a pellet sample was controlled with a hot stage (Mettler Toledo Inc. Switzerland) with accuracy of $\pm 0.1{ }^{\circ} \mathrm{C}$. Molecular weight determinations were performed using a gel permeation chromatography (GPC) instrument (Waters 2414 refractive index detector coupled with a Waters 717 plus Auto-sampler and Waters 600 Controller) with polystyrene standards as reference and tetrahydrofuran (THF) as the eluent. The rheological behavior of the polymers was investigated using a Rheometer Physica MCR301 with $15 \mathrm{~mm}$ parallel plates. Prior to any test the zero-gap between the parallel plates was calibrated at $5{ }^{\circ} \mathrm{C}$ above their clearing temperature. In the measurements, the sample was placed between preheated fixtures and $15 \mathrm{~min}$ were allowed to reach thermal equilibrium, before the gap was set to $0.2 \mathrm{~mm}$. For temperature changes, the control system needed about $5 \mathrm{~min}$ to reach a target equilibrium temperature with an error of $1 \sim 2{ }^{\circ} \mathrm{C}$. For dynamic oscillatory shearing the linear viscoelastic region of $0.1 \%$ strain was first obtained by strain sweep tests and no pre-shear was applied.

\section{Synthesis of macromer}

Synthetic routes for the target macromer are shown in Scheme 1.

Reaction conditions:

a) i. p-Butoxyphenol, ii. Toluene/conc. $\mathrm{H}_{2} \mathrm{SO}_{4}, \mathrm{HBO}_{3}$ iii. Reflux for $48 \mathrm{~h}$ with Dean-Stark trap

b) i. $\mathrm{K}_{2} \mathrm{CO}_{3}$ /acetone, ii. $\mathrm{Br}-\mathrm{CH}_{2}-\mathrm{CH}_{2}-\mathrm{CH}_{2}-\mathrm{CH}_{2}-\mathrm{CH}_{2}$ $\mathrm{CH}_{2}-\mathrm{Br}$

c) i. $\mathrm{KHCO}_{3}$

d) i. Hydroquinone/DMF ii. $100{ }^{\circ} \mathrm{C}$ for $24 \mathrm{~h}$.

Synthesis of 4-butoxyphenyl 6-hydroxynaphthalene-2-carboxylate (1)

In a $250 \mathrm{ml}$ two necks round bottom flask, $p$-butoxyphenol $(0.032 \mathrm{~mol})$ and 6-hydroxy-2-napthaonic acid $(0.038 \mathrm{~mol})$ were added in $50 \mathrm{ml}$ dried toluene. Concentrated sulfuric $(0.003 \mathrm{~mol})$ and boric $(0.003 \mathrm{~mol})$ acids were added subsequently. The mixture was then refluxed for $48 \mathrm{~h}$ using DeanStark trap to remove the produced water. After completion of the reaction, the solvent was removed under reduced 
Scheme 1 Synthetic route of the macromer (DM1)

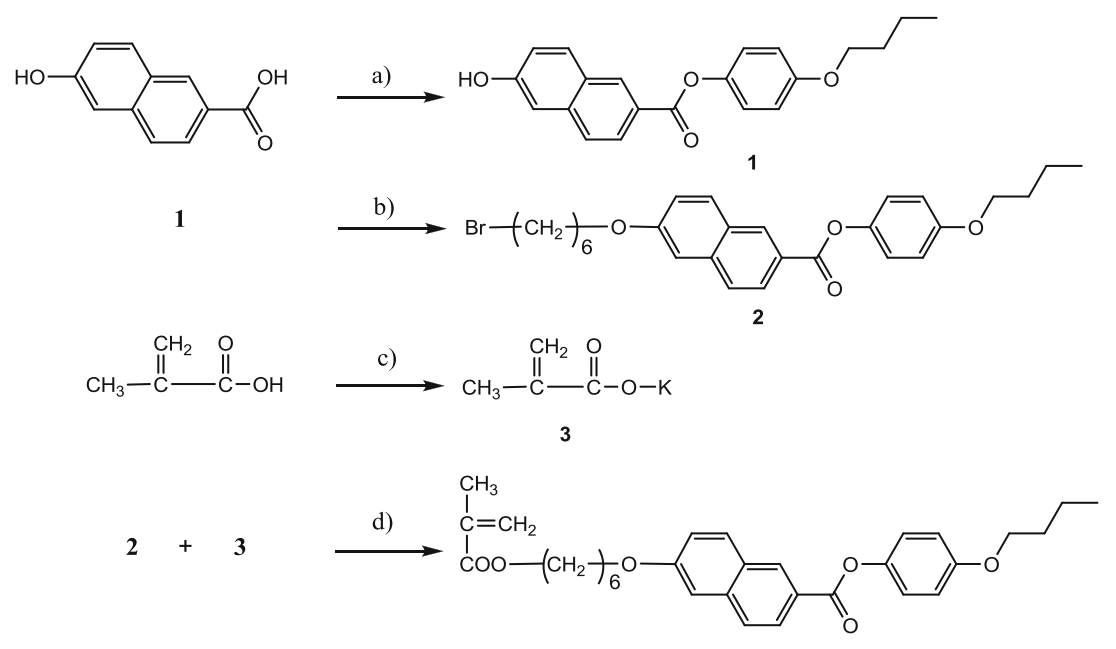

pressure and the product was washed with a mixture of petroleum ether $\left(40-60^{\circ} \mathrm{C}\right)$ and $n$-hexane $(1: 1)$. Acetonitrile was then added into the reaction mixture and heated to dissolve the product. The insoluble solid was then removed by hot filtration. The filtrate was then kept at $0{ }^{\circ} \mathrm{C}$ for $12 \mathrm{~h}$ and the solid was re-filtered. The solid was again dissolved in hot toluene and filtered to remove unreacted 6-hydroxy2-napthaonic acid. The filtrate was then kept at $0{ }^{\circ} \mathrm{C}$ for $12 \mathrm{~h}$ and the product was filtered to get white crystal product. The product was dried at $40{ }^{\circ} \mathrm{C}$ under vacuum with $40 \%$ yield. Mp: $180{ }^{\circ} \mathrm{C} .{ }^{1} \mathrm{H}$ NMR, $\delta$ (ppm, DMSO, $400 \mathrm{MHz}$ ) $10.3(\mathrm{H}, \mathrm{s}, \mathrm{Np}-\mathrm{OH}), 8.7(\mathrm{H}, \mathrm{s}, \mathrm{Np}-\mathrm{H}), 7.8-8.1$ (3H, m, Np-H), 7.2 (4H, m, Ph-H), $7.0(2 \mathrm{H}, \mathrm{m}, \mathrm{Ph}-\mathrm{H}), 3.9$ (t, $\left.2 \mathrm{H},-\mathrm{OCH}_{2}-\right)$, 1.65-1.72 (m, 2H, $\left.-\mathrm{CH}_{2}-\right), 1.39-1.48$ $\left(\mathrm{m}, 2 \mathrm{H},-\mathrm{CH}_{2}-\right)$, 0.89-0.94 (m, 3H, $\left.-\mathrm{CH}_{3}\right) .{ }^{13} \mathrm{C}$ NMR, $\delta$ (ppm, DMSO, $100 \mathrm{MHz}) 131.1(-\mathrm{OC}=\mathrm{O}-), 126.3,125.1$, $122.4,119.5,114.6,108.5$ (aromatic carbons), 67.2, 30.5, $18.5\left(-\mathrm{CH}_{2}-\right), 13.4\left(-\mathrm{CH}_{3}\right)$.FT-IR, $3480(-\mathrm{OH}), 2873-2960$ (alkyl), $1710(-\mathrm{C}=\mathrm{O}), 1434-1500 \quad(-\mathrm{C}=\mathrm{C}-\mathrm{Ar})$, 1185 (ester), 800-875 (p-Ar) $\mathrm{cm}^{-1}$.

Synthesis of 4-butoxyphenyl 6-(6-bromohexyloxy) -2-naphthoate (2)

In a $250 \mathrm{ml}$ two necks round bottom flask, a mixture of (1) $(0.02 \mathrm{~mol}), 1,6$-dibromohexane $(0.20 \mathrm{~mol})$, potassium carbonate $(0.02 \mathrm{~mol})$ and distilled acetone $(50 \mathrm{ml})$ was refluxed under stirring for $24 \mathrm{~h}$. After completion of the reaction, the reaction mixture was filtered and the precipitate washed thoroughly with acetone. The acetone was then removed under reduced pressure. After removing solvent, a mixture of petroleum ether $\left(40-60{ }^{\circ} \mathrm{C}\right)$ and hexane (1:1) was added. The precipitate was filtered off and recrystallized twice from ethanol with hot filtration. The white solid product was dried at $40{ }^{\circ} \mathrm{C}$ under vacuum to give $67 \%$ yield. Mp: $80{ }^{\circ} \mathrm{C} .{ }^{1} \mathrm{H}$ NMR, $\delta$ (ppm, $\left.\mathrm{CDCl}_{3}, 400 \mathrm{MHz}\right) 8.69$ (s, 1H, Np-H), 8.13-8.16 (dd, 1H, Np-H), 7.78-7.93 (dd, 2H, Np-H), 7.14-7.24 (m, 4H, Ar-H), 6.93-7.00 (m, 2H, Ph-H), 4.11-4.14 $\left(\mathrm{t}, 2 \mathrm{H},-\mathrm{OCH}_{2}-\right), 3.97-4.00\left(\mathrm{t}, 2 \mathrm{H},-\mathrm{CH}_{2}-\mathrm{Br}\right)$, $3.43-3.47\left(\mathrm{t}, 2 \mathrm{H}, \quad \mathrm{Ar}-\mathrm{CH}_{2}-\right), 1.86-1.97$ $\left(\mathrm{m}, 4 \mathrm{H},-\mathrm{CH}_{2}-\right), 1.76-1.83\left(\mathrm{~m}, 2 \mathrm{H},-\mathrm{CH}_{2}-\right)$ 1.4-1.5 $\left(\mathrm{m}, 6 \mathrm{H},-\mathrm{CH}_{2}-\right), 0.89-0.94\left(\mathrm{~m}, 3 \mathrm{H},-\mathrm{CH}_{3}\right) .{ }^{13} \mathrm{C} \mathrm{NMR}$, $\delta\left(\mathrm{ppm}, \mathrm{CDCl}_{3}, 100 \mathrm{MHz}\right) 131.6(-\mathrm{OC}=\mathrm{O}-), 131.0$, $127.0,126.2,122.5,120.0,115.1,106.5$ (aromatic carbons), 68.1 $\left(-\mathrm{CH}_{2}-\right)$, 33.8, 32.7, 31.4, 29.0, 27.9, 25.4, $19.3\left(-\mathrm{CH}_{2}-13.9\left(-\mathrm{CH}_{3}\right)\right.$. FT-IR, 2865-2932 (alkyl), $1730 \quad(-\mathrm{C}=\mathrm{O}), 1390-1500 \quad(-\mathrm{C}=\mathrm{C}-\mathrm{Ar}), 1197$ (ester), 811-859 (p-Ar) $\mathrm{cm}^{-1}$.

Synthesis of 4-butoxyphenyl 6-(6-(methacryloyloxy) hexyl)-2-naphthoate (DM1)

In a $250 \mathrm{ml}$ two necks round bottom flask, methacrylic acid $(3.35 \mathrm{mmol})$ was added slowly to potassium hydrogen carbonate $(3.35 \mathrm{mmol})$ at room temperature to form potassium methacrylate. A solution of (2) $(2.24 \mathrm{mmol})$ and hydroquinone $(0.025 \mathrm{mmol})$ in DMF $(50 \mathrm{ml})$ was added slowly into the previously prepared potassium methacrylate solution. The reaction mixture was heated with stirring at $100{ }^{\circ} \mathrm{C}$ for $24 \mathrm{~h}$. Thereafter the solvent was removed under vacuum followed by addition of $100 \mathrm{ml}$ water at room temperature. The solid was again filtered and dissolved in dichloromethane. The organic phase was washed twice by $5 \% \mathrm{NaOH}$ solution and twice by distilled water, followed by solvent removal under reduced pressure. The white solid was filtered and recrystallized twice from ethanol and dried at $40{ }^{\circ} \mathrm{C}$ under vacuum to give $55 \%$ yield. Mp: $103{ }^{\circ} \mathrm{C} .{ }^{1} \mathrm{H}$ NMR, $\delta$ (ppm, $\left.\mathrm{CDCl}_{3}, 400 \mathrm{MHz}\right) 8.61$ (s, H, Np-H), 8.05-8.08 (dd, 1H, NpH), 7.70-7.81 (dd, 2H, Np-H), 7.05-7.15 (m, 4H, Ar-H), 6.85-6.89 (m, 2H, Ph-H), $6.03\left(\mathrm{H}, \mathrm{s},=\mathrm{CH}_{2}\right), 5.46-5.48(\mathrm{~m}$, $\left.\mathrm{H},=\mathrm{CH}_{2}\right) 4.09-4.12\left(\mathrm{t}, 2 \mathrm{H},-\mathrm{OCH}_{2}-\right), 4.02-4.06(\mathrm{t}, 2 \mathrm{H}, \mathrm{Ph}-$ $\mathrm{CH}_{2}-$ ), 3.88-3.92 (t, $\left.2 \mathrm{H}, \mathrm{Ar}-\mathrm{CH}_{2}-\right)$, 1.86-1.87 (t, 3H, $-\mathrm{CH}_{3}$ ) 1.78-1.85 (m, $\left.2 \mathrm{H},-\mathrm{CH}_{2}-\right), 1.63-1.74\left(\mathrm{~m}, 4 \mathrm{H},-\mathrm{CH}_{2}-\right)$ 1.4-1.5 (m, 6H, $-\mathrm{CH}_{2}-$ ), 0.89-0.94 (t, 3H, $\left.-\mathrm{CH}_{3}\right) .{ }^{13} \mathrm{C} \mathrm{NMR}, \delta$ (ppm, $\left.\mathrm{CDCl}_{3}, \mathrm{MHz}\right)$ 131.6, $130.9(-\mathrm{OC}=\mathrm{O}), 126.9,126.1,122.4$, 
Table 1 Polymerization of Macromer DM1

\begin{tabular}{lllll}
\hline Sample & $\begin{array}{l}{[\mathrm{M}]_{0} /[\mathrm{I}]_{0} /} \\
{[\mathrm{C}]_{0} /[\mathrm{L}]_{0}{ }^{\mathrm{a}}}\end{array}$ & $\begin{array}{l}M_{w} \\
(\text { Cal. })\end{array}$ & $\begin{array}{l}M_{w} \\
(G P C)\end{array}$ & $\begin{array}{l}\text { PDI } \\
\left(M_{w} / M_{n}\right)^{\mathrm{b}}\end{array}$ \\
\hline DP1M1 & $40 / 1 / 1.5 / 2$ & 20,184 & 10,475 & 1.17 \\
DP2M1 & $60 / 1 / 1.5 / 2$ & 30,276 & 10,163 & 1.16 \\
DP3M1 & $80 / 1 / 1.5 / 2$ & 40,368 & 12,817 & 1.16 \\
\hline
\end{tabular}

${ }^{\text {a }}$ Feed molar ratio; $[M]$ macromer; $[I]$ initiator; $[C]$ catalyst; $[L]$ ligand

${ }^{b}$ Molecular weights and polydispersity index (PDI) values were measured by GPC, using THF as an eluent, polystyrene as a standard. $M_{n}$, number average molecular weight; $M_{w}$, weight average molecular weight

120.0, 115.1, 106.5 (aromatic carbons), 125.0 (C), 68.1, 64.6 $\left(-\mathrm{CH}_{2}-\right), 31.3,29.0,28.5,25.7,19.2\left(-\mathrm{CH}_{2}-\right), 18.3,13.9$ $\left(-\mathrm{CH}_{3}\right)$. FT-IR, 2871-2932 (alkyl), 1709-1730 $(-\mathrm{C}=\mathrm{O})$, 1390-1500 (C=C Ar), 1197 (ester), 811-859 (p-Ar) $\mathrm{cm}^{-1}$.

\section{Synthesis of polymers}

Polymers (DP1M1-DP3M1) were synthesized by living ATRP by using 2-bromoisobutyrate (EBriB), $\mathrm{CuBr}$ and $\mathrm{N}$, N,N',N',N'-pentamethyldiethylenetriamine (PMDETA) as an initiator, catalyst and ligand respectively.

\section{Polymer DP1M1}

$\mathrm{CuBr}(0.05 \mathrm{mmol})$, and macromer DM1 (1.3 mmol) were added to a three neck round bottom flask. The flask was sealed with a rubber septum, degassed and back-filled with nitrogen gas three times. $2 \mathrm{ml}$ deoxygenated anisole was added via syringe, followed by deoxygenated PMDETA (0.064 mmol). After stirring for $30 \mathrm{~min}$ at room temperature, the reaction mixture was placed in a preheated oil bath at $90{ }^{\circ} \mathrm{C}$ for $7 \mathrm{~h}$. The solution turned light green as the $\mathrm{CuBr} / \mathrm{PMDETA}$ complex was formed. After the majority of the metal complex had formed, ethyl 2-bromoisobutyrate (EBriB) $(0.032 \mathrm{mmol})$ was added to the reaction flask. The solution was then passed through a neutral $\mathrm{Al}_{2} \mathrm{O}_{3}$ column with THF as an eluent to remove the catalyst, $\mathrm{CuBr}$. The product was concentrated under reduced pressure and precipitated twice into 15 fold excess of methanol. The white product of polymer was collected by filtration and dried under vacuum. $M_{w}=10,475 \mathrm{~g} / \mathrm{mol}$ and PDI $\left(M_{w} / M_{n}\right)=1.17$.

\section{Polymer DP2M1}

Polymer DP2M1 was synthesized according to the procedure described for polymer DP1M1 except for the amount of initiator, $\operatorname{EBriB}(0.0211 \mathrm{mmol}) . M_{w}=10,163 \mathrm{~g} / \mathrm{mol}$ and PDI $\left(M_{w} / M_{n}\right)=1.16$.

\section{Polymer DP3M1}

Polymer DP3M1 was synthesized according to the procedure described for polymer DP1M1 except for the amount of initiator, EBriB (0.0159 mmol). $M_{n}=12,817 \mathrm{~g} / \mathrm{mol}$ and PDI $\left(M_{w} / M_{n}\right)=1.16$.
Fig. $1{ }^{1} \mathrm{H}$ NMR spectra of (a) macromer DM1 and (b) polymers DP1M1-DP3M1 in $\mathrm{CDCl}_{3}$
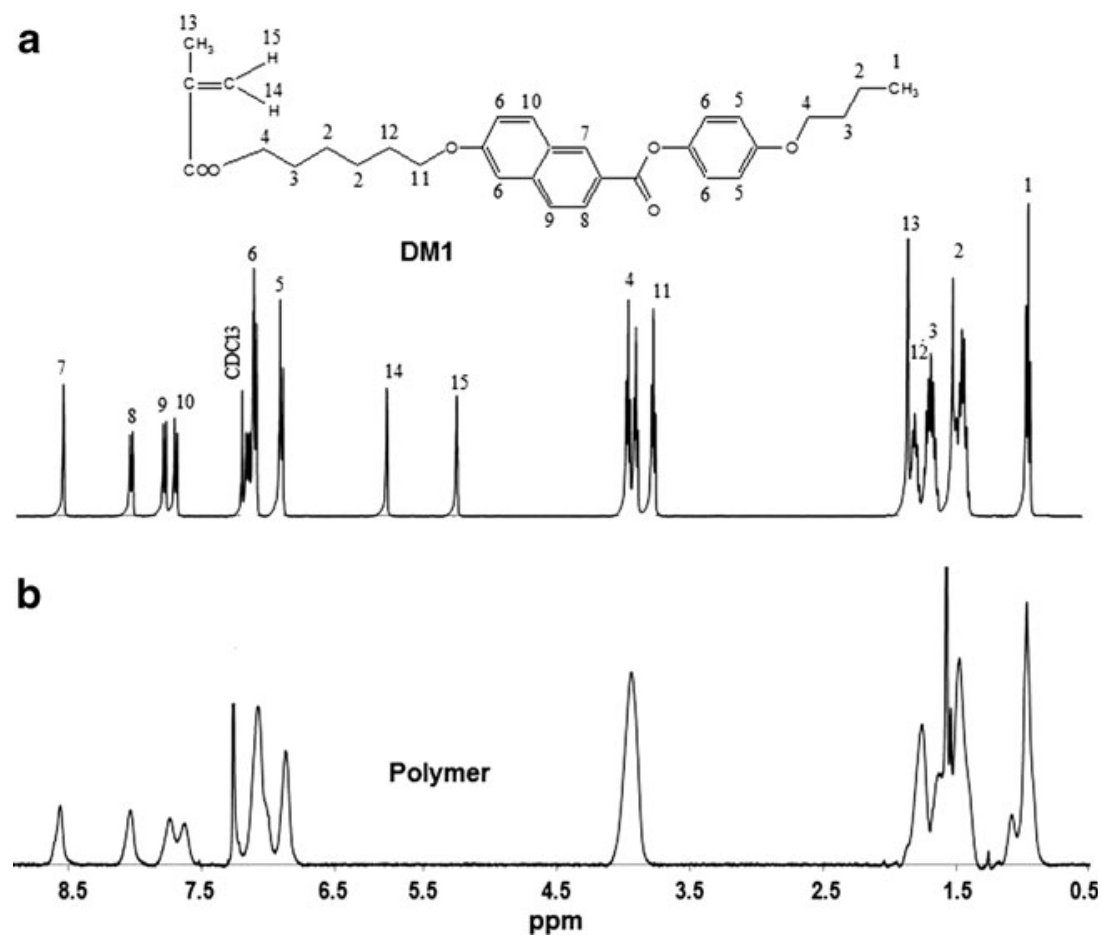
Table 2 Phase behavior and thermal properties of macromer and polymers

\begin{tabular}{|c|c|c|}
\hline \multirow[t]{2}{*}{ Sample } & \multicolumn{2}{|c|}{ Phase transitions $\left({ }^{\circ} \mathrm{C}\right)^{\mathrm{a}, \mathrm{b}}$ (corresponding enthalpy changes, $\mathrm{J} \mathrm{g}^{-1}$ ) } \\
\hline & Heating & Cooling \\
\hline DM1 & g 49.9 S $86.8(0.97) \mathrm{N} 103.6(0.96) \mathrm{I}$ & I $102.3(-1.04) \mathrm{N} 85.5(-1.02) \mathrm{S}$ \\
\hline DP1M1 & g $62.8 \mathrm{~S} 149.4(1.39) \mathrm{N} 162.8(2.48) \mathrm{I}$ & I $161.6(-2.27) \mathrm{N} 148.2(-1.24) \mathrm{S}$ \\
\hline DP2M1 & g $62.6 \mathrm{~S} 149.1(1.41) \mathrm{N} 162.6(2.32) \mathrm{I}$ & I $161.3(-2.43) \mathrm{N} 147.9(-1.15) \mathrm{S}$ \\
\hline DP3M1 & g 68.4 S150.6 (0.97) N 163.3 (1.82) I & I $162.01(-2.08) \mathrm{N} 149.3(-1.44) \mathrm{S}$ \\
\hline
\end{tabular}

${ }^{\mathrm{a}}$ Transition temperatures $\left({ }^{\circ} \mathrm{C}\right.$ ) and enthalpies (in parentheses, $\mathrm{J} \mathrm{g}^{-1}$ ) were measured by DSC (at a heating and cooling rate of $10{ }^{\circ} \mathrm{C} / \mathrm{min}$ )

${ }^{\mathrm{b}} \mathrm{g}$ glassy; $S$ Smectic phase; $N$ nematic phase; $I$ isotropic phase

\section{Results and discussion}

Synthesis and characterization

A macromer with electron releasing $\left(-\mathrm{OC}_{4} \mathrm{H}_{9}\right)$ terminal group was synthesized by acid-catalyzed esterification $[17,18]$ of 4butoxyphenol and 6-hydroxy-2-napthaonic acid. The synthetic route for the macromer DM1 is outlined in Scheme 1. ATRP has been proven to be a successful polymerization technique to prepare polymers for a variety of monomers with narrow polydispersity $[10,19,20]$. All polymers were prepared using $\mathrm{CuBr}$, PMDETA, and EBriB as the catalyst, ligand and initiator respectively in anisole and the reaction conditions were all kept at $90{ }^{\circ} \mathrm{C}$ for $7 \mathrm{~h}$. The relative molecular weights and polydispersity index (PDI) values of the polymers were determined by GPC. The polymerization conditions and GPC results are shown in Table 1.

The macromer and polymers had good solubility at room temperature in common organic solvents, such as tetrahydrofuran, ethyl acetate and dichloromethane. Since the macromer had good solubility in methanol, it was chosen to remove unreacted macromer from polymers in the normal precipitation process. The chemical structures of the macromer and polymers were confirmed by ${ }^{1} \mathrm{H}$ NMR spectroscopy as shown in Fig. 1. The spectral assignments clearly supported the proposed structures: DM1 showed characteristic proton peaks of the vinyl groups at 5.48-6.03 ppm (denoted as 14 and 15 in
(Fig. 1a), the sharp and clearly separated proton resonances of macromer disappeared after polymerization (Fig. 1b), while broad and overlapped resonances of LC mesogen attached to polymeric back bones appeared at nearly the same positions.

Liquid crystalline properties

The thermal properties and the phases of the macromer and polymers were studied by DSC, POM and SAXS. The phase transition temperatures and changes in enthalpy $(\Delta \mathrm{H})$ obtained during the first cooling and the second heating cycles are summarized in Table 2. The enthalpy changes observed are nearly independent of the molecular weights and this observation is in agreement with results obtained by Trimmel et al. [21]. They found that the polymers containing more than ten repeating units gave independent enthalpy changes to the molecular weight but were strongly dependent on spacer length, with a minimum $n=6$. From the data listed in Table 2, the mesophase temperature ranges of polymers are greater than the macromer. This indicates that the polymerization effect can stabilize and widen the mesophase temperature range and that the increase in molecular weight definitely increases the mesomorphic-mesomorphic and mesomorphicisotropic phase transition temperatures.

Figure 2 represents the DSC thermograms of heating and cooling cycles of the macromer at a rate of $10{ }^{\circ} \mathrm{C} / \mathrm{min}$. The macromer exhibits a glass transition temperature, $\mathrm{T}_{\mathrm{g}}$, at
Fig. 2 DSC thermograms for the macromer DM1

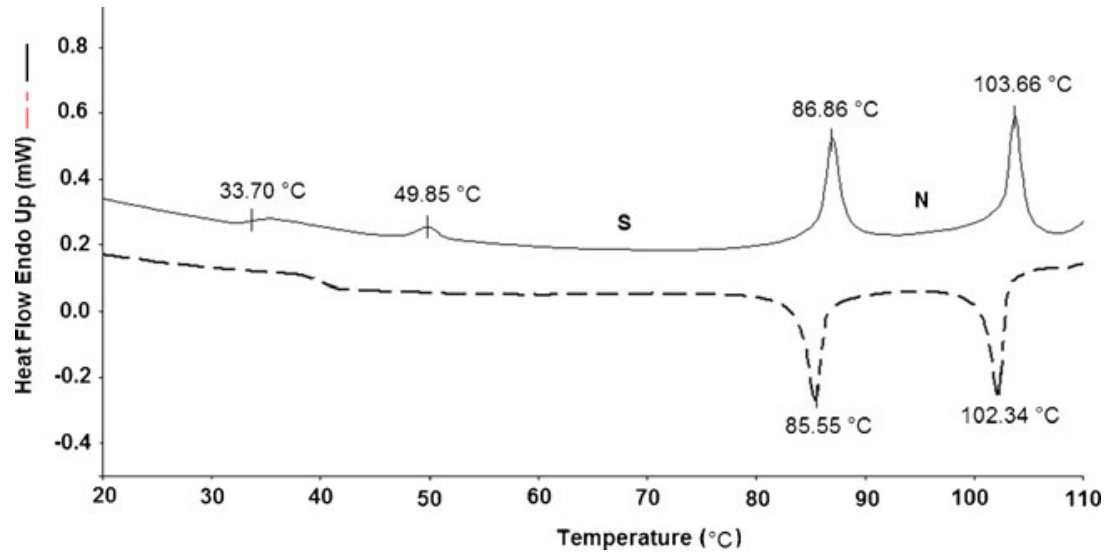


$33.7^{\circ} \mathrm{C}$ followed by a nematic and smectic mesophases which undergo isotropization at $103.6{ }^{\circ} \mathrm{C}$ during second heating scan. The thermal transitions are enantiotropic, where the liquid crystal phase exists upon heating and cooling. Two peaks at $102.3^{\circ} \mathrm{C}$ and $85.5^{\circ} \mathrm{C}$ associated with the isotropicnematic and nematic-smectic transitions respectively are observed during the cooling scan. Figure 3 shows the POM of macromer texture obtained at different temperatures. Upon cooling from isotropic melt, schlieren texture of nematic mesophase appears at $101.9^{\circ} \mathrm{C}$ (Fig. 3a). Certain region of focal conic fan texture which is characteristic of a smectic mesophase at $83.8^{\circ} \mathrm{C}$ becomes dark indicating the isotropic liquid area (Fig. 3b). When the macromer is cooled to room temperature from its isotropic state, it solidifies and its crystalline phase appears lumber-like mosaic textures (Fig. 3c). The mesophase temperature range is found to be very broad (49.85-103.66 $\left.{ }^{\circ} \mathrm{C}\right)$ which might be attributed to the presence of crankshaft structure of the naphthalene that can decrease the freedom of molecule movement [22].

Figure 4 represents the DSC thermograms of heating and cooling cycles of polymers at rate of $10^{\circ} \mathrm{C} / \mathrm{min}$. All the polymers enter the nematic mesophase at $148{ }^{\circ} \mathrm{C}$ and smectic mesophase at $161{ }^{\circ} \mathrm{C}$ during the cooling scans. Figure 5 represents the POM textures of the polymers upon cooling from isotropic point. The schlieren textures appear with droplets when the polymers were cooled at $165.7^{\circ} \mathrm{C}$ from isotropic temperature as shown in Fig. 5a. The droplets are characteristic of nematic mesophase because they occur nowhere else [23]. There are many point singularities with two dark brushes in the schlieren textures, which further confirm the nematic nature of the mesophase because such singularity is not compatible with the smectic $C$ phase $[24,25]$. Upon further cooling, coarse textures of disclination loops are formed (Fig. 5b). The stripes of the textures disappear upon heating and regenerated by cooling. When the polymers are cooled at $108{ }^{\circ} \mathrm{C}$, the striped loops grow to striated feather textures (Fig. $5 \mathrm{c}$ ).

SAXS experiments were performed to elucidate the mesophase textures. Figure 6 shows the SAXS intensity

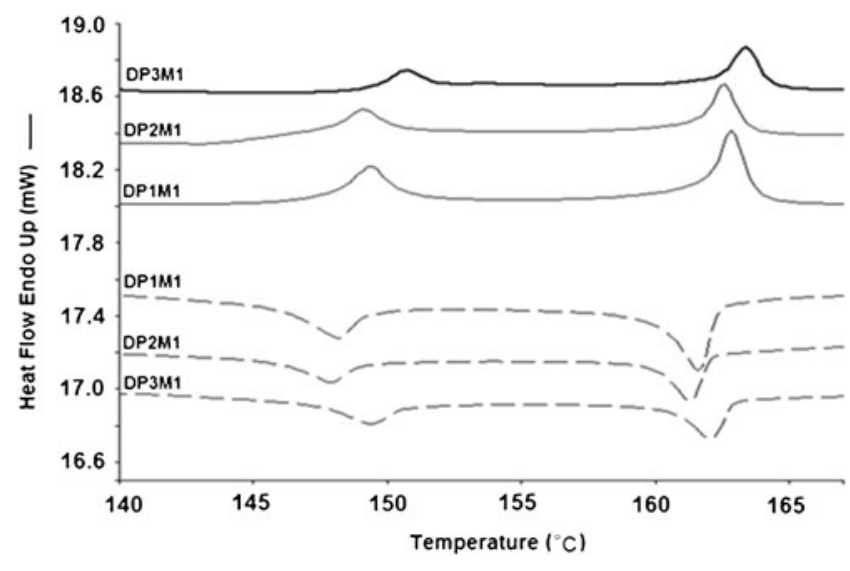

Fig. 4 DSC thermograms for the polymers

profiles of macromer DM1 at room temperature and $100{ }^{\circ} \mathrm{C}$. At room temperature, the sample shows a sharp scattering signal in the low $q$ region $\left(2.2 \mathrm{~nm}^{-1}\right)$ indicating a typical smectic phase texture and an intense broad peak in the higher $q$ region $\left(3.27 \mathrm{~nm}^{-1}\right)$ which indicates that only a short-range order exists in the molecular lateral packing [26]. The layer periodicities calculated for the first sharp peak are $2.86 \mathrm{~nm}$ and $1.92 \mathrm{~nm}$ for the broad peak. After heating at $100{ }^{\circ} \mathrm{C}$, the sharp peak disappears while the broad peak remains, indicating that the sample has entered the nematic phase. From the results of DSC, POM and SAXS, we can conclude that the transitions from isotropic to nematic phase has occurred at higher temperature and that from nematic to smectic phase has occurred at lower temperature.

\section{Rheological properties}

Determination of linear viscoelastic (LVE) region of materials is important in performing dynamic rheological characterizations which are independent of applied strains. Figure 7 shows the strain dependence of storage $\left(G^{\prime}\right)$ and loss $\left(G\right.$ ") moduli of the polymers at $170{ }^{\circ} \mathrm{C}$ with $\omega=10 \mathrm{rad} / \mathrm{s}$
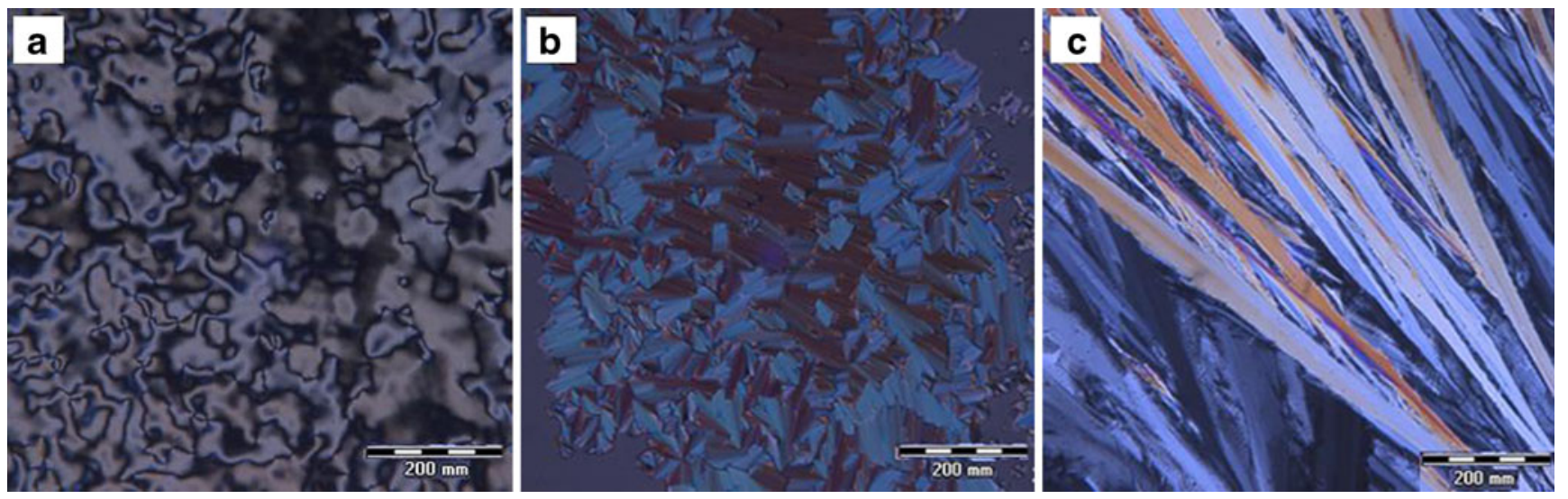

Fig. 3 POM textures of macromer DM1. a Nematic at $101.9{ }^{\circ} \mathrm{C}(\mathbf{b})$ Smectic at $83.8^{\circ} \mathrm{C}(\mathbf{c})$ Crystalline at room temperature 

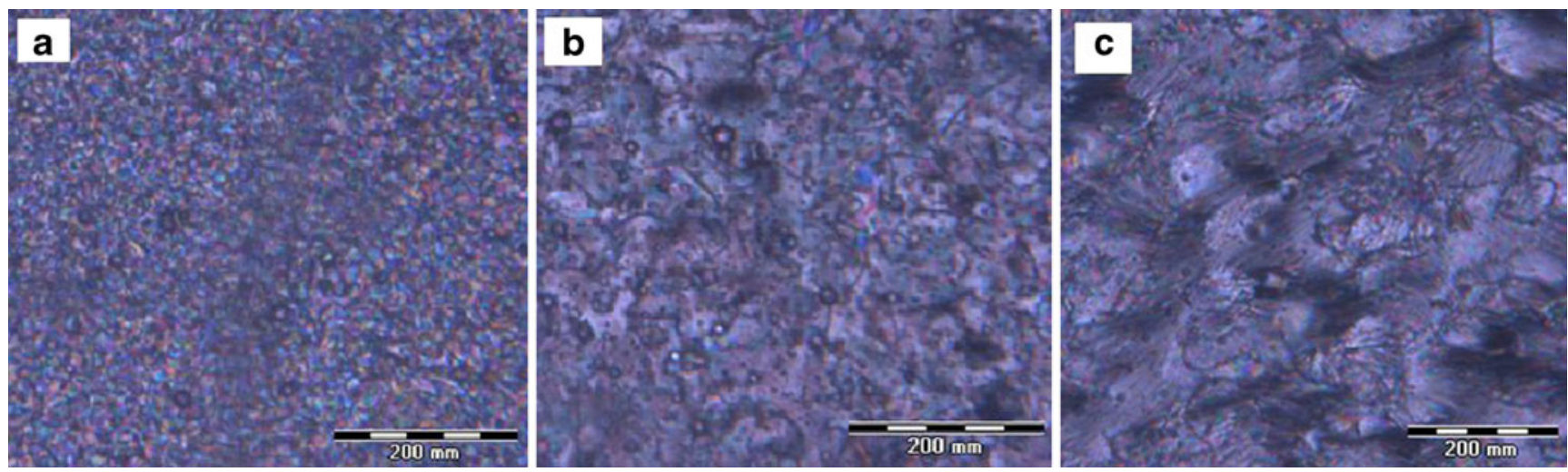

Fig. 5 POM textures of polymer DP1M1. a $165.7^{\circ} \mathrm{C}$ (b) $162{ }^{\circ} \mathrm{C}$ (c) $108{ }^{\circ} \mathrm{C}$

by strain amplitude sweep experiments. It can be seen that $G$ " is greater than $G$ ' in both polymers and largely insensitive to strain amplitude. As such, the polymers do not form a viscoelastic gel.

Figure 8 represents the viscosity properties of the polymers over the temperature range of phase transitions. Both polymers exhibit Bingham body-like flow behavior at $100^{\circ} \mathrm{C}$ and $110{ }^{\circ} \mathrm{C}$ which shows "three region flow curves" as characterized by Onogi and Asada [27, 28]. At low values of shear rate $\left(\dot{\gamma}<1 \mathrm{~s}^{-1}\right)$, both polymers exhibit a shear thinning behavior and the viscosity decreases. A Newtonian behavior appears at intermediate values of shear rate $\left(1 \mathrm{~s}^{-1}<j<10 \mathrm{~s}^{-1}\right)$, where the domains appear to decrease in size with increasing shear rate. At this stage the viscosity is relatively insensitive to shear rate. At higher values of $\left(\gamma>10 \mathrm{~s}^{-1}\right)$, a strong thinning behavior appears where the domain structure is not evident at this stage [27]. These results are in agreement with the results of Kannan et al. [29] and Dan et al. [30] which suggested that the large amplitude oscillatory shear orientated the SCLCPs.

However, as the temperature is increased from $120^{\circ} \mathrm{C}$ to $150{ }^{\circ} \mathrm{C}$, the polymers exhibit shear thinning behavior where the particles rearranged resulting in reduced flow resistance

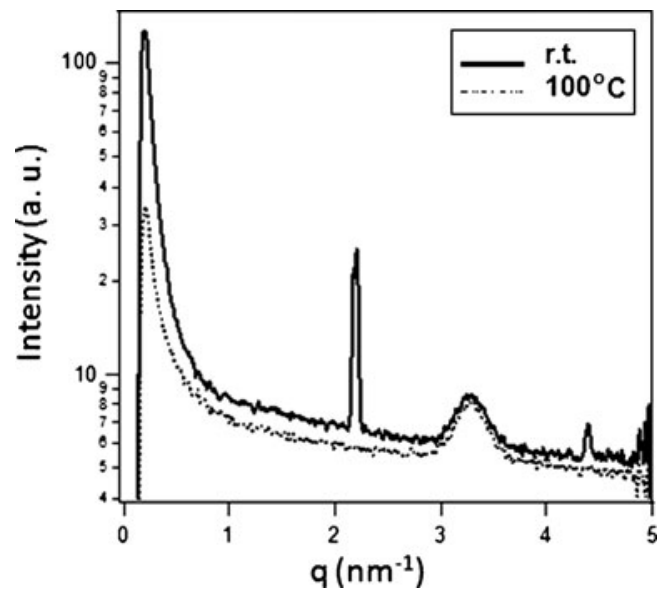

Fig. 6 Small angle X-ray scattering of macromer DM1 and consequently lower the viscosity of the polymers with increased in shear rate. The polymers exhibit Newtonian behavior at low shear rate, followed by strain hardening behavior at higher shear rate at $160{ }^{\circ} \mathrm{C}$ and $170{ }^{\circ} \mathrm{C}$ which are in the isotropic region for both polymers. Rubin et al. [31] reported that the strain hardening behavior is probably due to the tendency of the mesogens to orient perpendicular to the backbone in the SCLCPs. The mesogens which are attached to a strand may be forced to adopt an intermediate orientation between the backbone segment and local orientation of the director.

Figure 9 shows plots of $\log G^{\prime}$ vs $\log \omega$ and plots of $\log$ $G$ ” vs $\log \omega$ for polymer DP2M1 at $100{ }^{\circ} \mathrm{C}$ to $150^{\circ} \mathrm{C}$ in the smectic region and $160{ }^{\circ} \mathrm{C}$ in the nematic region. The values of $G$ ' and $G$ " in the smectic region are much higher than those in the nematic region, attributing to the 3-dimensional textures in smectic textures and 1-dimensional textures in the nematic phase. This finding is similar to that of Kim and Han [32] who studied the effect of bulkiness of pendant side group semiflexible main-chain liquid crystal polymers (MCLCPs).

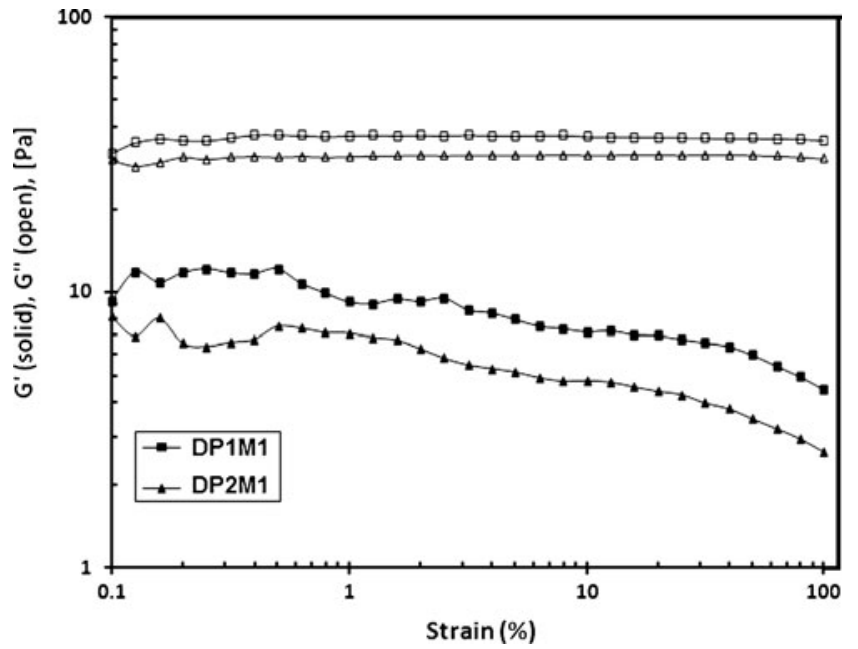

Fig. 7 Strain amplitude sweep of polymers at $170{ }^{\circ} \mathrm{C}$ 


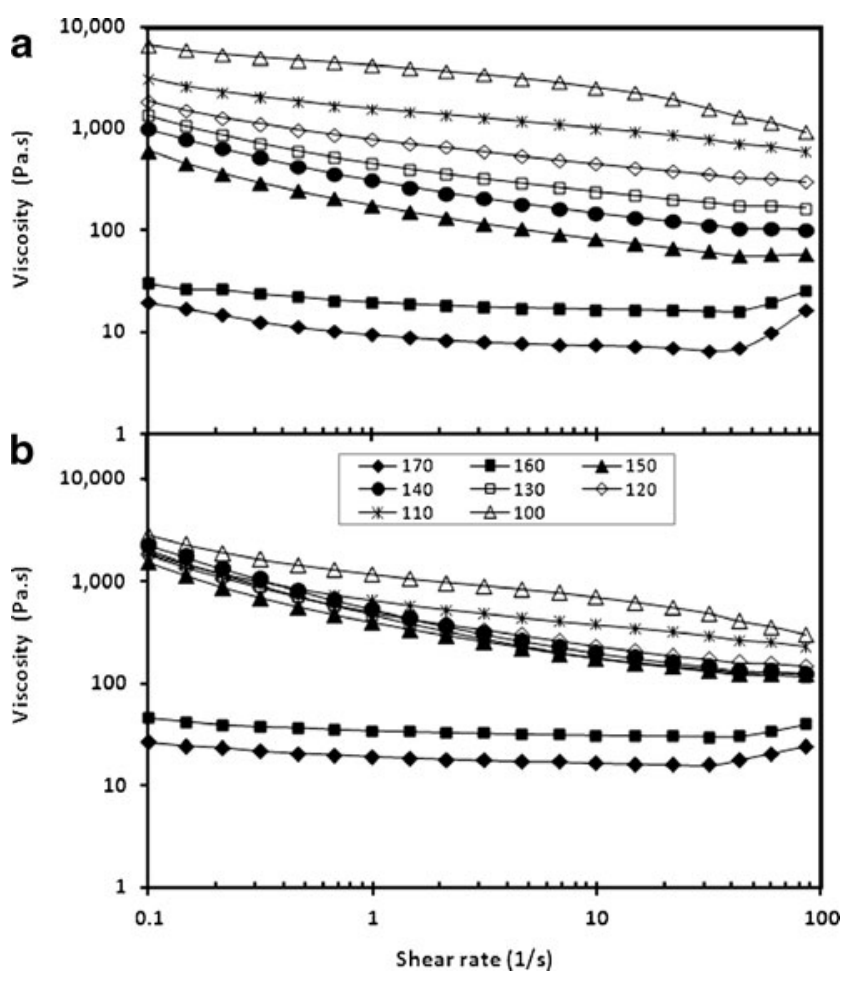

Fig. 8 Viscosity of polymers (a) DP2M1 (b) DP3M1 at various temperatures

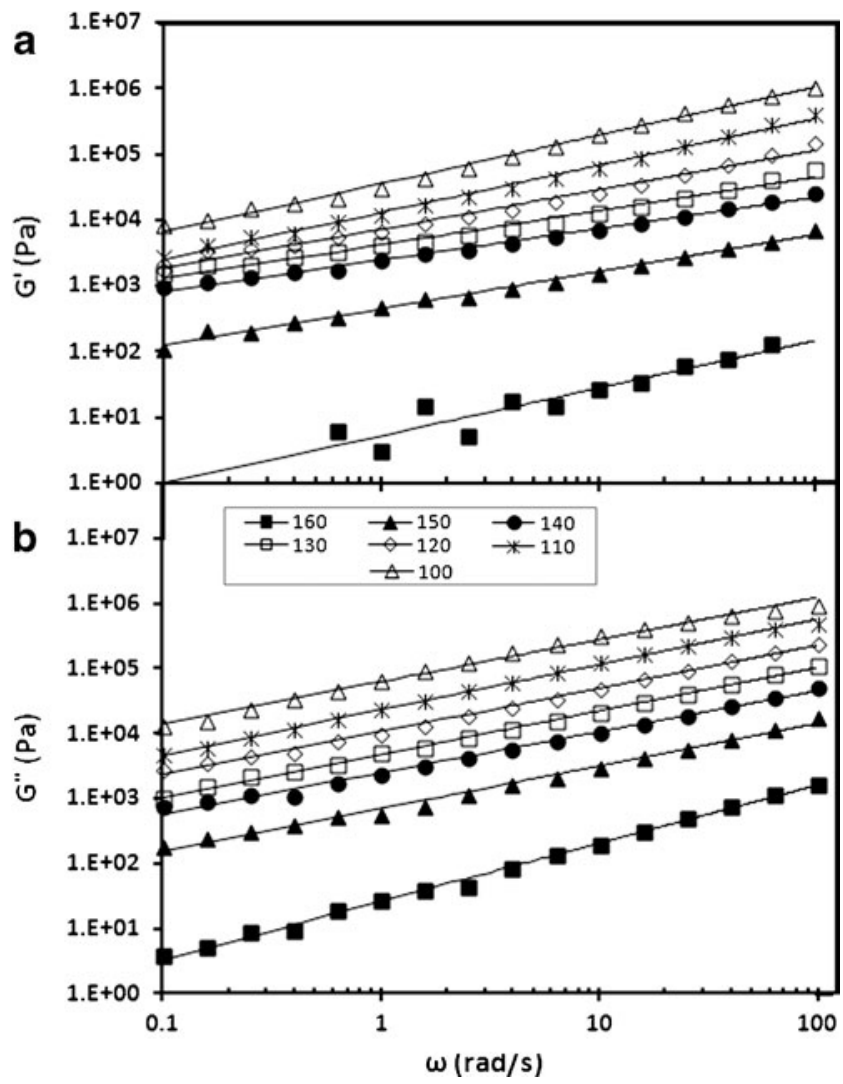

Fig. 9 Plots of $\log G^{\prime}$ vs $\log \omega$ and $\log G^{\prime \prime}$ vs $\log \omega$ for polymer DP2M1 at various temperatures
At low frequency values, both $G^{\prime}$ and $G^{\prime \prime}$ tend to level off and do not follow the typical terminal behavior where $G^{\prime} \propto \omega^{2}$ and $G^{\prime \prime} \alpha \omega^{2}$. The slope of $G^{\prime}$ in the terminal region decreases from 0.73 to 0.56 as the temperature increases from $100{ }^{\circ} \mathrm{C}$ to $150{ }^{\circ} \mathrm{C}$. As the temperature increases from $100{ }^{\circ} \mathrm{C}$ to $150{ }^{\circ} \mathrm{C}$ the slope of the loss modulus $G$ " decreases from 0.69 to 0.62 . From this observation, the polymer exhibits solid-like behavior when $T \leq 150{ }^{\circ} \mathrm{C}$. The slopes of $G^{\prime}$ and $G$ " are subsequently increased to 0.97 and 0.94 respectively when the temperature increases to $160{ }^{\circ} \mathrm{C}$. At this temperature, the polymer exhibits liquid-like behavior. The general trends resemble the unshifted linear viscoelastic data as reported by Auad et al. [33] for the smectic SCLCPs. The changes in the linear viscoelastic response are a common signature of ordering transitions.

In the isotropic phase, molecular weight of a polymer has a strong influence on the rheology where an entanglement plateau emerges. Nevertheless, the polymer, DP2M1, has a low molecular weight which is less than the molar mass of entanglement and also the smectic phase rheology is dominated by the layer structure and is comparatively insensitive to the molecular weight. Therefore, it is not expected to have a plateau in the terminal region. Similar trend of behavior are also obtained for DP3M1 polymer.

Figure 10 shows a plot of $\log \left|\eta^{*}\right|$ vs $\log \omega$ for polymer DP2M1 at various temperatures, where $\left|\eta^{*}\right|$ is the complex viscosity defined by $\left|\eta^{*}\right|=\left[\left(G^{\prime} / \omega\right)^{2}+\right.$ $\left[(G " / \omega)^{2}\right]^{1 / 2}$. As the temperature increases from $100{ }^{\circ} \mathrm{C}$ to $150{ }^{\circ} \mathrm{C}$, the polymer enters the smectic phase which exhibits a strong frequency dependence of $\left|\eta^{*}\right|$ at low angular frequencies and then Newtonian behavior is observed at $160{ }^{\circ} \mathrm{C}$. At this temperature, the polymer enters the nematic phase which exhibits a weak frequency dependence over the entire range of angular frequencies tested. The abrupt decrease of $\left|\eta^{*}\right|$ values is due to

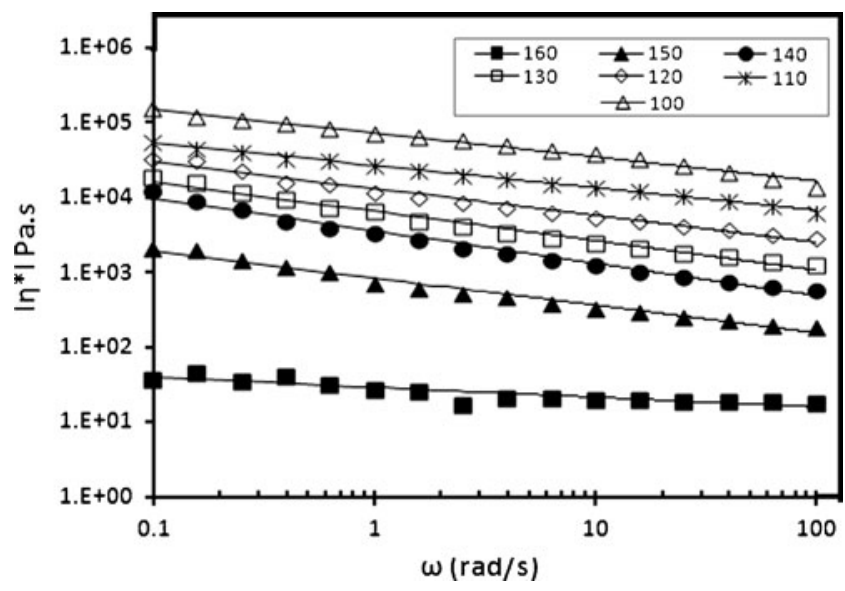

Fig. 10 Plots of $\log \left|\eta^{*}\right|$ vs $\log \omega$ for polymer DP2M1 at various temperatures 
breakdown of 3-dimensional smectic order to 1-dimensional nematic order where, in nematic phase the molecules would exhibit preferential orientation during shear flow. A similar observation has been reported by Lee and Han [34] for their SCLCPs.

\section{Conclusions}

A new polymerizable macromer having naphthalene moiety and optically active species in the mesogen has been synthesized. A series of side chain liquid crystal polymers (SCLCPs) with different molecular weights and narrow polydispersities derived from this new macromer was successfully prepared by ATRP in anisole. The chemical structures of the macromer and polymers were confirmed by ${ }^{1} \mathrm{H} N M R,{ }^{13} \mathrm{C}$ NMR and FTIR while evidence of the liquid crystalline behavior of the macromer and polymers were shown by DSC, POM and SAXS. All the synthesized macromer and polymers showed nematic and smectic mesophase with different textures. The viscoelasticity properties carried out in smectic to nematic region showed that the frequency behavior of the polymers in a smectic phase is characterized by the leveling off in the storage modulus, $G$ ' at low frequencies. Complex viscosities, $\left|\eta^{*}\right|$ of the smectic phase exhibited a shear thinning behavior over the shear rates investigated.

Acknowledgments The authors would like to acknowledge financial support from University of Malaya for the research grants PS490/2010B and RG151/11AFR, and also to thank Professor Yusuke Kawakami, JAIST, Japan for some of the chemicals for this research work.

Open Access This article is distributed under the terms of the Creative Commons Attribution License which permits any use, distribution, and reproduction in any medium, provided the original author(s) and the source are credited.

\section{References}

1. Collings P (2002) Princeton Univ. Press, New Jersey
2. Salehli F, Yildiz S, Ozbek H, Uykur E, Gursel YH, Durmaz YY (2010) Polymer 51:1450-1456

3. Anuragudom P, El-daye J, Chinwangso P, Advincula R, Phanichphant S, Lee T (2011) Polym Int 60:660-665

4. Watanabe M, Tsuchiya K, Shinnai T, Kijima M (2012) Macromolecules 45:1825-1832

5. Nair B, Gregoriou V, Hammond P (2000) Polymer 41:2961-2970

6. Wittmann J, Meyer S, Damman P, Dosiere M, Schmidt H (1998) Polymer 39:3545-3550

7. Yuan G, Zhao Y (1997) Polymer 38:119-125

8. Zhang H, Lei X, Su Z, Liu P (2007) J Polym Res 14:253-260

9. Yu W-N, Liu S-X, Wang H-M, Tian R (2012) J Polym Res 19:1-7

10. Wang LY, Li KC, Lin HC (2010) Polymer 51:75-83

11. Xiong L, Liang H, Wang R, Chen L (2011) J Polym Res 18:10171021

12. Coessens V, Matyjaszewski K (2010) J Chem Educ 87:916-919

13. Matyjaszewski K (2004) Mol Cryst Liq Cryst 415:23-34

14. Ramakrishnan A, Dhamodharan R (2000) J Macromol Sci, Pure Appl Chem 37:621-631

15. Jeyasheela S, Subramanian K (2012) Mol Cryst Liq Cryst 557:161-175

16. Yang I, Chang S (2002) J Polym Res 9:163-168

17. Lowrance W Jr (1971) Tetrahedron Lett 12:3453

18. Van Meter J, Klanderman B (1973) J Am Chem Soc 95:626627

19. Patten T, Matyjaszewski K (1998) Adv Mater 10:901-915

20. Wang XZ, Zhang HL, Shi DC, Chen JF, Wang XY, Zhou QF (2005) Eur Polym J 41:933-940

21. Trimmel G, Riegler S, Fuchs G, Slugove C, Stelzer F (2005) In: Buchmeiser M (ed) Metathesis polymerization. Springer, Berlin

22. Chen BK, Tsay SY (2005) Polymer 46:8624-8633

23. Kong X, Tang BZ (1998) Chem Mater 10:3352-3363

24. Demus D (1999) Wiley-VCH, Germany

25. Stegemeyer H (1994) Springer, Germany

26. Wang Q, Yang C, Xie H, Wang X, Zhang H (2010) Liq Cryst 37:435-443

27. Onogi S, Asada T (1988) In: Astarita G, Marrucci G, Nicolais L (eds) Rheology and rheo-optics of polymer liquid crystals in Rheology. Plenum Press, New York

28. Lee H, Denn M (1999) Korea-Aust Rheol J 11:269-273

29. Kannan R, Kornfield J, Schwenk N, Boeffel C (1993) Macromolecules 26:2050-2056

30. Dan K, Kim B, Han Y (2009) Macromol Res 17:313-318

31. Rubin SF, Kannan RM, Kornfield JA, Boeffel C (1995) Macromolecules 28:3521-3530

32. Kim D, Han C (2000) Macromolecules 33:3349-3358

33. Auad ML, Kempe MD, Kornfield JA, Rendon S, Burghardt WR, Yoon K (2005) Macromolecules 38:6946-6953

34. Lee K, Han C (2003) Macromolecules 36:8796-8810 